\title{
NOVO CLASSE A: A CRISE DE IMAGEM NO VÍDEO PUBLICITÁRIO DA MERCEDES-BENZ
}

JORGE FRANCISCO PUENTE ARNAO GALARRETA ADA CRISTINA MACHADO SILVEIRA ISABEL PADILHA GUIMARÃES 
NOVO CLASSE A: A CRISE DE IMAGEM NO VÍDEO PUBLICITÁRIO DA MERCEDES-BENZ

Resumo: Este artigo analisa o vídeo publicitário do carro Novo Classe A, da Mercedes-Benz e a polêmica gerada em função da inserção do funk "Passinho do Volante" na sua trilha sonora. Busca-se compreender o choque entre os imaginários da Mercedes-Benz e do Funk gerado na construção deste vídeo, a partir de uma análise comparativa entre dois vídeos produzidos em 2013, dos dois carros mais acessíveis da marca, o Novo Classe A e o CLA.

Palavras-Chave: Crise de imagem; Funk; Imaginário; Identidade; Vídeo publicitário

NUEVO CLASE A: LA CRISIS DE IMAGEN EN EL VIDEO PUBLICITÁRIO DE LA MERCEDES-BENZ

Resumen:Este artículo analiza el video publicitário del carro Nuevo Clase A, de la Mercedes-Benz y la polémica generada en función de la inserción del Funk "Passinho do Volante" en su banda sonora. Se busca comprender el choque de imaginarios generado en la construcción de este video mediante un análisis comparativo entre los dos videos producidos en 2013, de los dos carros más accesibles de la marca, el Nuevo Clase A y el CLA.

Palabras-Clave: Crisis de imagen; Funk; Imaginario; Identidad; Video publicitário

NEW A-CLASS: IMAGE CRISIS IN THE PROMOTIONAL VIDEO OF THE MERCEDES-BENZ

Abstract: This article analyzes the promotional video of the Mercedes-Benz New A-Class and the controversy arising from using the funk music 'Passinho do Volante' in its soundtrack. Our aim is to understand the clash of imaginaries produced in the making of this video. To this end, we will make a comparative analysis between two videos produced in 2013 for the two most affordable cars of the brand: New A-Class and the CLA-Class.

Keywords: Image crisis; Funk; Imaginary; Identity; Promotional Video 


\section{INTRODUÇÃO}

Para que uma empresa esteja em harmonia, a sua imagem deve ser o reflexo da sua identidade. A representação que os consumidores têm sobre ela, pode ser reforçada por meio de ações publicitárias. Entretanto, uma imagem incongruente da identidade da empresa, criará um conflito, resultado do imaginário que o público consumidor irá criar e que poderá ser diferente da filosofia da empresa.

Este artigo tem como objetivo compreender como um vídeo publicitário pode criar uma crise de imagem para uma marca, utilizando como exemplo, o vídeo de lançamento do carro Novo Classe A da Mercedes-Benz, a partir da utilização de uma trilha sonora, com um estilo musical (neste caso, o Funk) que apresenta características de um imaginário, diferente-daquelas apresentadas pela marca. Cria-se um conflito entre os imaginários da Mercedes-Benz (empresa do modelo do carro Novo Classe A) e do Funk.

Para a Mercedes-Benz a intenção é rejuvenescer a marca, atingindo um novo público. A agência de publicidade defende a ideia de que o vídeo foi realizado com a finalidade de mostrar um posicionamento mais jovem perante o seu público. Como pode ser visto no trecho retirado da revista sobre carros Quatro Rodas (http://quatrorodas.abril.com.br/noticias/fabricantes/polemicaclasse-funk-lek-lek-737776.shtml):

A própria Mercedes-Benz o vê como "um carro voltado para um público mais jovem, e foi por isso que nos permitimos investir mais no humor e ser mais ousado na comunicação", segundo o gerente de comunicação corporativa da Mercedes-Benz, Marcel Dellabarba.

Por meio de sua assessoria de imprensa, a Mercedes-Benz ressaltou que o vídeo "não é a campanha publicitária do Classe A", e sim um vídeo viral para redes sociais, criado pela área de marketing da marca em conjunto com a agência AbBat/Tesla com o objetivo de "chamar a atenção para o lançamento do carro e impactar nas mídias sociais".

Por este motivo, iremos realizar uma análise do vídeo e exemplificando-o com outro, da mesma marca, que tem o mesmo objetivo de apresentar um carro novo e mais jovial. A partir desta pesquisa, buscamos compreender se o 
formato do audiovisual do Novo Classe A é adequado para reforçar a imagem da marca Mercedes-Benz e, ao mesmo tempo, transformá-la em uma imagem mais jovial, sendo coerente com o objetivo da empresa.

\section{IDENTIDADE E IMAGINÁRIO}

A identidade de uma empresa refere-se à maneira como ela se comporta, suas influências internas e externas, suas crenças, sua personalidade. "A identidade corporativa reflete e projeta a real personalidade da organização. É a manifestação tangível, o auto-retrato da organização ou a soma total de seus atributos, sua comunicação, suas expressões, etc." (KUNSCH, 2003, p. 172).

Para criar a identidade de uma empresa é necessário seguir passos e ações constantes que darão características a ela, à marca e aos seus produtos, seguindo principalmente as suas características históricas. Desta maneira, uma identidade é criada ao longo do tempo para os consumidores.

Também deve-se construir um conjunto sinóptico das associações positivas. Há de se considerar cinco dimensões que podem transmitir significado. Atributos: Deve ocasionar lembranças fortes de atributos na mente do cliente; Benefícios: Sugerem benefícios ao invés de somente aspectos; Valores da empresa: Conotam valores e caráter da empresa mantenedora da marca; Personalidade: Exibe personalidade quando averiguado suas associações; Usuários: Indica o público alvo que quer atingir. Estas propriedades são a base para se desenvolver a "identidade" da marca, que define o "código genético" da mesma. (AZEVEDO, OLIARI, NEOTTI, s/d, p. 4)

A imagem de uma empresa diz respeito à sua apresentação ao público, a partir da sua identidade, devendo demonstrar os valores, os objetivos e as crenças para o público e ambos, identidade e imagem, precisam ser coerentes. “A imagem de empresa é a representação mental, no imaginário coletivo, de um conjunto de atributos e valores que funcionam como um estereótipo e determinam a conduta e opiniões desta coletividade." (COSTA, 2012, p.58).

Este conjunto de valores e atributos mostrados ao público auxilia na construção coletiva de um imaginário acerca da empresa. Essa construção, que não tem um ponto concreto de origem, é influenciada por diferentes elementos, como a cultura, pertencimento e emoção. "O imaginário é determinado pela ideia de 
fazer parte de algo". (MAFFESOLI, 2005, p. 37). O autor faz referência ao imaginário político, mas aqui, pode ser traçado um paralelo com a publicidade.

O imaginário político trabalha a argumentação através de um arsenal de mecanismos emocionais, como os símbolos de um partido, as datas que devem ser comemoradas, os heróis e mitos que devem ser lembrados, os ritos que precisam ser atualizados. O marketing, em política, resume o cruzamento da razão - o planejamento publicitário racional - com a valorização do emocional. De resto, toda a publicidade funciona assim (MAFFESOLI, 2001, p.5)

Neste sentido, a publicidade guia-se pelo emocional, para além da argumentação persuasiva ou racional.

\subsection{Imagem, Marca e Vídeos promocionais}

Para criar a sua imagem, uma empresa utiliza-se de ferramentas de publicidade, marketing e relações públicas, pensando no seu público e como ele irá perceber estas ações de imagem da empresa.

A imagem corporativa define como a empresa é percebida, o que ela parece ser, ou seja, a percepção psicológica de sua identidade. O processo de formação de uma imagem é resultado de atributos representativos para um indivíduo, provenientes dos meios de comunicação de massa, das relações interpessoais e da sua experiência pessoal. (BITTAR, 2012, p.27)

Para auxiliar na construção de imagem, a empresa tem a sua marca, que exerce um papel importante neste processo. Os valores e as crenças que os consumidores têm sobre uma empresa, são associados a uma marca, que a representará perante o mercado e o público.

Na concepção holística, as marcas são vistas como objetos vivos que se relacionam com os consumidores, ou seja, a marca poderá ser, dessa forma, entendida como uma promessa de um compósito de atributos (reais versus ilusórios,racionais versus emocionais, tangíveis versus intangíveis) geradores de satisfação. (LOURO, 2000, p. 27) 
Quando uma empresa rompe com os valores, crenças e objetivos que ela defende, poderá gerar uma crise de imagem. Em uma campanha de divulgação de um produto, se os consumidores não associam este à marca, a crise pode estabelecer-se. "Uma crise de imagem, antes de tudo, é uma crise de confiança, de credibilidade, de reputação. O que uma empresa vende não é um produto, mas uma marca e com ela uma série de associações." (VASQUEZ, 2007, p. 14).

Os vídeos promocionais são importantes na divulgação de um produto ou uma marca, no relacionamento com o público e no reforço de sua identidade, pois contribuem na construção da imagem, a partir dos valores e características identitárias de uma empresa. Segundo Bittar, (2012, p.29) "se a empresa não sabe bem qual é sua identidade, não consegue passar uma boa imagem. Há então os casos presenciados diariamente. Diz-se que o cliente é especial, enquanto fazem com que ele tenha um tratamento abaixo da crítica".

A publicidade exerce um importante papel na construção de imagem, fortalecendo ou enfraquecendo a identidade, os valores e as crenças da empresa. Por isto, é necessário muito cuidado para que uma não seja incongruente com a outra.

A comunicação é resultante do processo de criação e de fortalecimento de uma cultura organizacional (formal e informal), na qual deve residir a estruturação da identidade corporativa. Quando a identidade é claramente diferenciada, resulta em estilo ao qual podemos chamar de imagem (BITTAR, 2012, p. 29).

A imagem e o áudio apresentados na sequência do vídeo são elementos construtivos para a imagem pública do produto que será apresentada aos consumidores e espectadores, que por sua vez, vão interpretá-lo de acordo com o imaginário formado a respeito da marca.

Eles não buscam informar, querem apenas divertir e persuadir o telespectador com histórias que vendem sonhos e status social. Em muitos casos, o publicitário (juntamente, com a produtora) opta por utilizar somente trilha e efeitos sonoros [...] para tornar o enredo mais íntimo e lúdico, fazendo com que o consumidor se sinta o próprio personagem da história. (DE DEUS \& DE ASSIS, 2008, p. 27) 
A trilha sonora escolhida pela produtora do comercial é pensada e posteriormente veiculada, para um público específico e pode ter o mesmo poder de persuasão da imagem, ou até superá-lo. Isto demonstra a importância do som em um vídeo publicitário.

As trilhas sonoras dos comerciais de televisão têm um segundo papel relevante na publicidade: podem segmentar o público-alvo do produto ou serviço fazendo isso de maneira sutil e quase imperceptível. A propaganda não precisa apontar diretamente em imagens e texto o seu consumidor em potencial, a trilha pode ser direcionada para um público-alvo especifico de acordo com a identificação do ritmo com seu público de interesse, sem que o resto da grande massa se sinta imediatamente excluída do contexto. (COELHO, 2008, p. 24)

Desta forma, a trilha pode ser excludente, visto que promove a seleção do público que irá gostar e aprovar o vídeo e é planejada, geralmente, por uma agência de comunicação responsável pela produção audiovisual que irá representar o produto/empresa/marca.

\subsection{História, Identidade e Imaginário da Mercedes Benz}

Em 1880, os fundadores Gottieb Daimler e Karl Benz, inventaram, separadamente, um motor de alta velocidade que utilizaram para o desenvolvimento das suas próprias empresas em transportes motorizados. Em 1883, Benz estabeleceu a sua empresa com o nome de Benz \& Co em Mannheim (Alemanha), enquanto Gottieb Daimler fundou, em 1890, a DMG (Daimler-Motoren-Gesellschaft). O Mercedes foi batizado pela DMG com este nome, graças a um acordo com um comprador australiano que adquiriu 36 automóveis e quis homenagear a filha cujo nome era Mercedes.

Em 1899, após a morte de Daimler, a DMG vendeu a marca "Daimler", preservando a marca Mercedes. Logo depois, Karl Benz, decidiu acrescentar o nome Benz aos automóveis Mercedes, ficando assim conhecida até hoje. O desejo de criar uma empresa inovadora os juntou, nascendo assim a "Benz e Daimler". O nome Mercedes foi registrado em 23 de Junho de 1902 e a marca propriamente dita, foi registrada em 26 de Setembro.

A marca Mercedes-Benz se posiciona perante o mercado como detentora de uma das mais avançadas tecnologias, além da elegância do design dos seus 
automóveis. Segundo o site oficial da Mercedes Benz: “Mundialmente, a Mercedes é símbolo da excelência automóvel e encontra-se firmemente assente, entre as marcas internacionais de luxo".

Em 2010, o slogan lançado pela marca reflete o conceito que ela quer passar para os seus consumidores, "The Best or nothing", ou seja, "O melhor ou nada”. Este slogan acompanha a Mercedes-Benz e é símbolo da imagem que a marca busca sobre os seus carros: serem os melhores.

A imagem que a Mercedes veicula, através dos vídeos, também é congruente a própria identidade. Os vídeos da marca costumam ter um apelo ao status e ao sucesso, ao desejo de consumo do possível comprador. Esta é a linha com a qual a marca trabalha a estratégia de persuadir o seu público-alvo, vinculando-se à elegância e ao sucesso, como por exemplo, o evento Mercedes-Benz Fashion Week', ou a propaganda que realizou em 2012 com Roger Federer, segundo melhor tenista do mundo, na época.

Quando um vídeo publicitário é realizado, o objetivo é apresentar o produto para os consumidores, informando as características que este possui. No vídeo do modelo do Novo Classe A, de 2013, da Mercedes, no Brasil, a estratégia foi ousada e causou polêmica entre os consumidores da marca. Segundo o site de comunicação Meio\&Mensagem (http://www.meioemensagem.com.br) , a trilha sonora foi a responsável pela reação do público.

A peça mostra imagens do novo Classe A fazendo manobras em um cenário futurista, com muitos efeitos de edição de imagem. A ideia é mostrar a segurança do veículo, já que é possível girar o volante de um lado para o outro em pista molhada sem grandes riscos, graças aos sistemas Steer Control e Adaptive Brake.

Até aí, tudo bem. O choque ocorre por causa da trilha escolhida: nada menos que o hit do funk "Passinho do Volante", conhecido nacionalmente pelo refrão “Ah, lelek, lek, lek, lek”.

1 É uma das quatro principais semanas de moda mundial realizada em fevereiro e setembro de cada ano. Antigamente conhecido como New York Fashion Week, mudou o nome em 2009 devido ao patrocínio da Mercedes-Benz. (http://www.mbfashionweek.com/) 
Segundo o mesmo site, esta é a linha de carro "popular" da Mercedes-Benz, assim como o modelo CLA, da mesma marca.

\subsection{História, Identidade e Imaginário do Funk}

O Funk é um ritmo musical criado na década de 1960, nos EUA e é o resultado de uma mistura entre soul, R\&B e Jazz. Em meados da mesma década, o Funk começa a ganhar reconhecimento através do músico James Brown e é neste momento que se torna um gênero musical.

Este Funk foi trazido ao Brasil no ano de 1969, por cantores como Gerson King Combo, que lançou o disco Gerson Combo Brazilian Soul, com sucessos brasileiros como Asa Branca executados com a batida importada dos Estados Unidos. Outros cantores conhecidos utilizaram este ritmo nas suas músicas, como Tim Maia, Carlos Dafé e Tony Tornado.

Também chegou ao Brasil um tipo de Funk influenciado por outro ritmo dos Estados Unidos, o Miami Bass, que apresenta músicas mais eróticas e batidas rápidas. Este ritmo foi difundido na década de 1980, mais especificamente nas favelas cariocas, e foi neste cenário que se consagrou. ?Essa adoção do funk por jovens suburbanos (principalmente os mais pobres entre os suburbanos) e favelados do Rio parece dificultar a penetração dessa música entre os jovens das camadas médias cariocas." (VIANNA, 1990, p. 246)

Em entrevista para o site G1 (http://g1.globo.com/), Leandro Petersen, filho do Big Boy (foi o mais importante Disc Jockey, na década de 1960), que realizou uma pesquisa sobre a história do Funk, salienta que

As pessoas têm mania de falar que o funk tem conotação sexual e costumo citar essa música como exemplo que é uma questão muito mais de movimento. Também tinha uma coisa de mau gosto para a sociedade. É mais ou menos a mesma coisa que falar 'tô ficando atoladinha' hoje. Só evoluiu dentro do mundo. Faz parte da questão do funk mesmo, do pobre, do excluído, que fala de conotação sexual, de violência. E esse é o primeiro funk de referência, que marcou uma geração.

Esta ideia é reforçada por outros autores que decifram a identidade do Funk a partir do seu significado simbólico e cultural no Brasil. 
Pelo apresentado, é plausível a constatação de que os funkeiros são o grupo social que mais sentimento de medo provoca nos nãofunkeiros, isso se dá, portanto, graças à representação socialmente construída a partir da qual se nega sua identidade e, portanto, sua forma de falar, se vestir, de andar, de gesticular, seus valores, sonhos e ideais. (MENDONÇA, 2011, p.13)

Ou seja, a identidade do não-funkeiros se revela a partir da diferença. O não-funkeiro é o que o funkeiro não é. Este último por sua vez, é visto como pobre e excluído.

Tal identidade, por um lado, se manifesta para os não-funkeiros a partir de uma estética e de um comportamento negado em termos valorativos porque não fazem parte do "cardápio do bom gosto" assim definido pelas camadas mais bem sucedidas e porque possuem aquele comportamento tido como oriundo de um habitus precário o qual não permite que se "vença na vida", portanto, é um comportamento que permite claramente identificar um sujeito que "não vai ser ninguém na vida". (MENDONÇA, 2011, p. 16)

A partir destas considerações, percebemos pelo imaginário criado a partir das características identitárias do Funk carioca, seja pelas letras com a temática da pobreza e da exclusão, ou pelos estereótipos definidos pelo outro (nãofunkeiro), que este ritmo musical é relacionado principalmente à pobreza, ao mau gosto e à violência.

O Funk "Passinho do Volante", veiculado no comercial a ser analisado, foi criado pelo MC Federado \& Os Leleks, grupo musical montado em 2012 e começou como uma brincadeira, através da gravação de um vídeo da música, com um custo de apenas 70 reais.

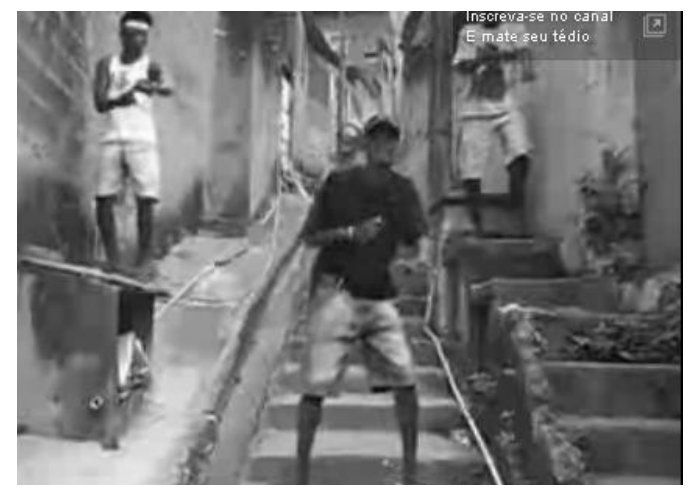

Imagem 1: vídeo do "Passinho do Volante" 
O vídeo (http://www.youtube.com/watch?v=ill_ODPwd40) já teve mais de dois milhões de acessos, e junto a outros clipes da mesma música contabiliza mais de 5 milhões de visualizações, apontando para o impacto que este funk alcançou. MC Federado \& Os Leleks dançam a coreografia da música em um ambiente que pode ser identificado como uma favela.

A música ficou conhecida quando o jogador de futebol do time do Santos, Neymar, comemorou um gol, dançando a coreografia deste funk. Depois dele, a comemoração com a dança foi repetida por diversos esportistas como o famoso corredor e recordista mundial dos 100 metros livres, Usain Bolt, a equipe Rio de Janeiro, de vôlei, campeã da Superliga de Vôlei em 2013, dentre outros.

\section{ANÁLISE dAS PEÇAS PUBLICITÁRIAS}

Após a abordagem sobre as questões de identidade e imagem, passa-se à análise do vídeo publicitário de lançamento, no Brasil, do carro Novo Classe A, e tomando como exemplo um vídeo produzido pela Mercedes-Benz, tendo como base o vídeo de lançamento do carro mais econômico da marca nos EUA, o CLA. Apesar de não serem do mesmo modelo, ambos os carros foram lançados em 2013, são os mais acessíveis da marca, economicamente e foram produzidos com o intuito de apostar no rejuvenescimento de seu público. O objetivo desta análise não é comparar os vídeos, mas sim trazer como exemplo a repercussão que tiveram, já que um mantém a imagem da Mercedes, exibindo luxo e sucesso, enquanto o outro utiliza a música estilo funk para apresentar o carro.

\subsection{Pacto com o Diabo}

A ação foi criada pela agência Merkley+Partners e, veículado em janeiro de 2013, na televisão em rede nacional nos Estados Unidos. (http://www.youtube. com/watch?v=LMvAZWgAfel). A trilha sonora do vídeo é a música Sympathy For The Devil, (Simpatia pelo Diabo) dos Rolling Stones, tema que faz referência ao enredo. Neste vídeo, o ator hollywodiano Willem Dafoe, que interpreta o Diabo, conversa com um jovem em um bar, que está em busca do sucesso. A trama do vídeo trata sobre a proposta do Diabo por um pacto, trocando a alma do jovem por fama e sucesso. O Diabo oferece uma caneta para o jovem e diz: "Faça um acordo comigo garoto e você pode ter o carro e tudo o que vai junto com ele". (Imagem 2) 


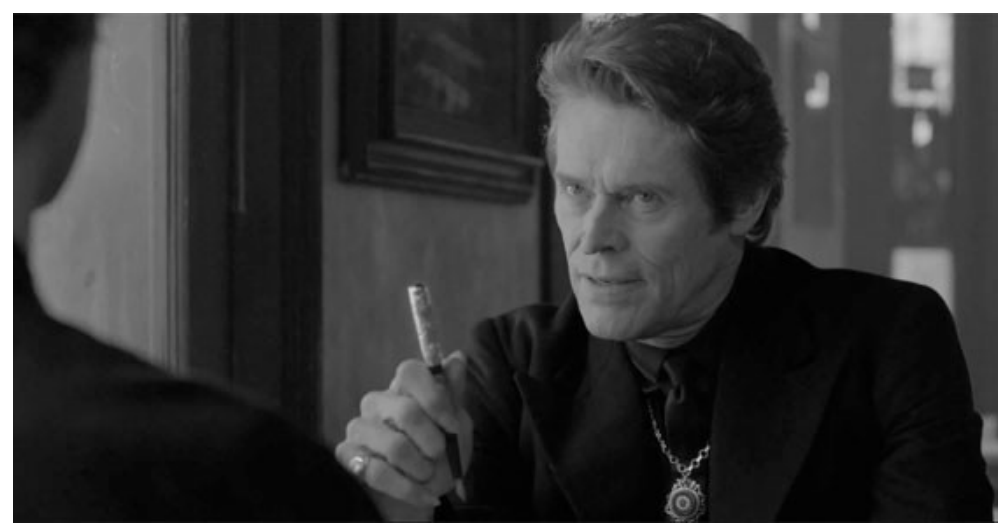

Imagem 2: O Diabo oferecendo a caneta

O jovem, ao receber a caneta, começa a imaginar como será a sua vida se assinar o contrato e ganhar o carro. Surge um brilho dos flashes de máquinas fotográfica, que remetem para a sua imaginação. Primeiramente, ele se torna uma celebridade e consegue conquistar a modelo americana Kate Upton.

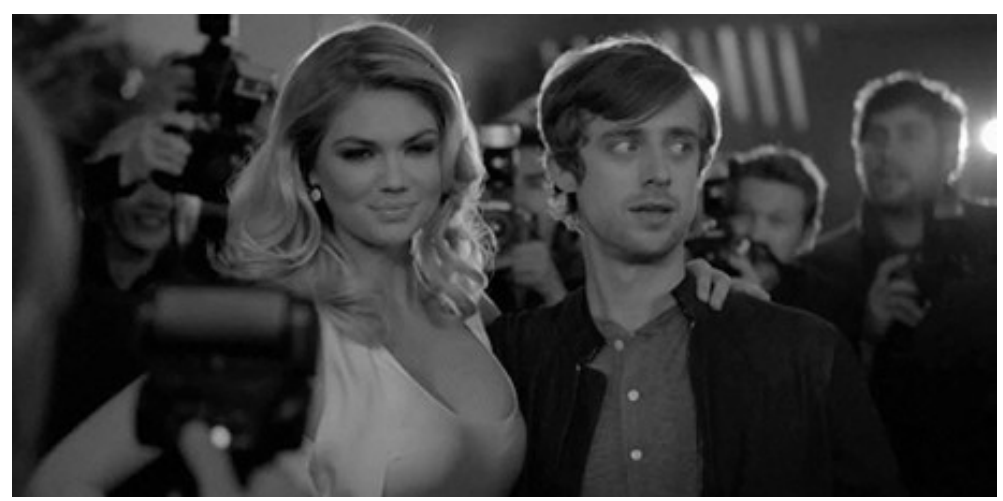

Imagem 3: Jovem com Kate Upton

O personagem vai a festas com artistas renomados da música, como o músico Usher. Nesta cena, predomina um tom azul metálico. (Imagem 4)

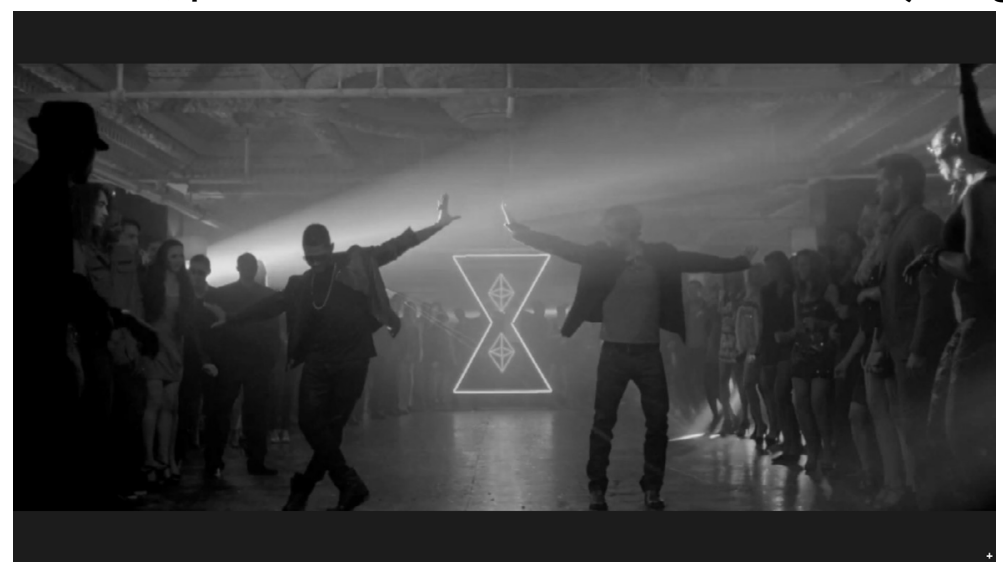

Imagem 4: Jovem dançando com Usher 
Na próxima cena, ele se torna destaque em diversas capas de revista. Os flashes de máquinas fotográficas iluminam o jovem, criando um clima de glamour e fama. (Imagem 5)

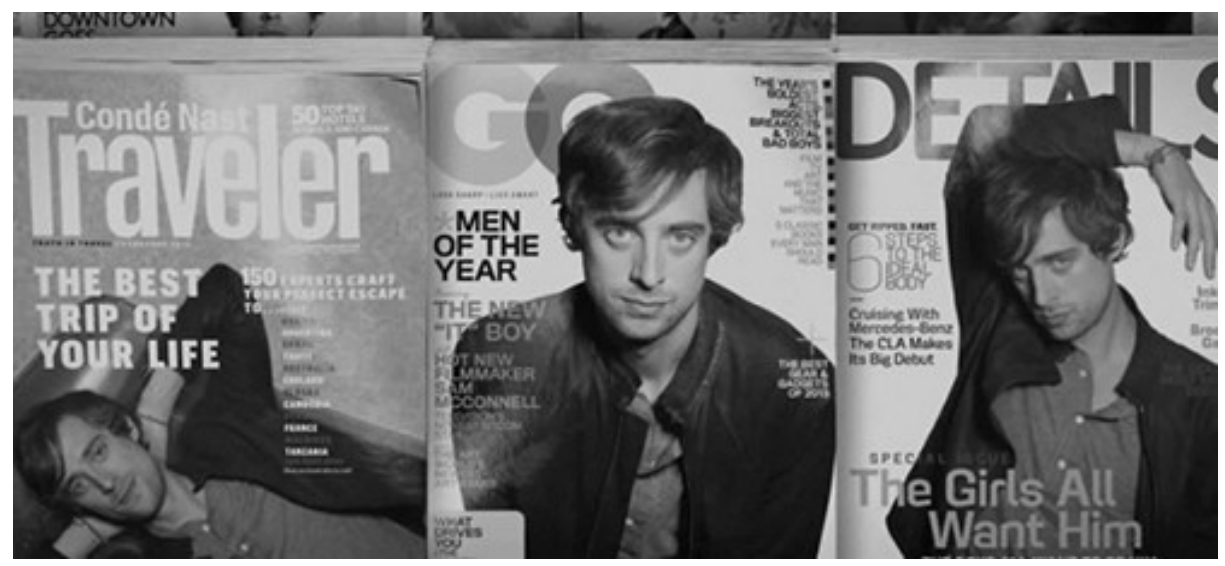

Imagem 5: Jovem na capa das revistas

Vale ressaltar que neste vídeo, o personagem convive com artistas famosos, reconhecidos internacionalmente. Ele também se torna conhecido, sendo retratado em várias capas de revistas, ficando tão famoso quanto os artistas com os quais contracena. Para fugir das admiradoras que o perseguem, ele invade uma corrida de carros e ultrapassa facilmente os outros veículos (Imagem 6), demonstrando, além de todos os benefícios simbólicos de ter este carro, uma característica técnica, que também é símbolo de poder: sua velocidade.

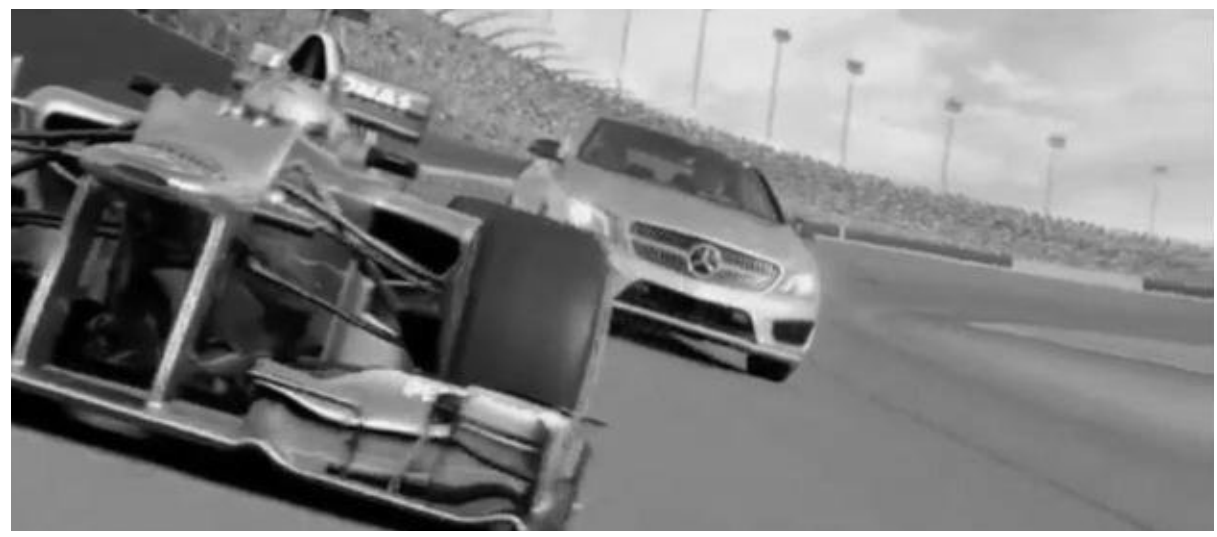

Imagem 6: O carro competindo em corridas

Este vídeo demonstra as vantagens de se possuir um carro da marca Mercedes Benz, que tornaria as pessoas bem sucedidas, com fama, status e luxo, características que a própria empresa valoriza e reforça na sua identidade e na 
sua imagem. Por mais que o vídeo publicitário seja direcionado para um público jovem, apresentando um dos carros de menos valor econômico, semelhante ao Novo Classe A, as características identitárias da empresa estão no vídeo e por isso, não causou polêmica entre os fãs da Mercedes-Benz no Facebook da empresa, segundo busca realizada na Fanpage da Mercedes-Benz USA, que teve 15.861 curtidas, 692 comentários, a maioria com conteúdo positivo, e 1016 compartilhamentos (Imagem 7) e nos blogs de comunicação do país, como por exemplo, The Communications Blog (http://thecommunicationsblog.com/).e TopRank Online Marketing (http://www.toprankmarketing.com/)

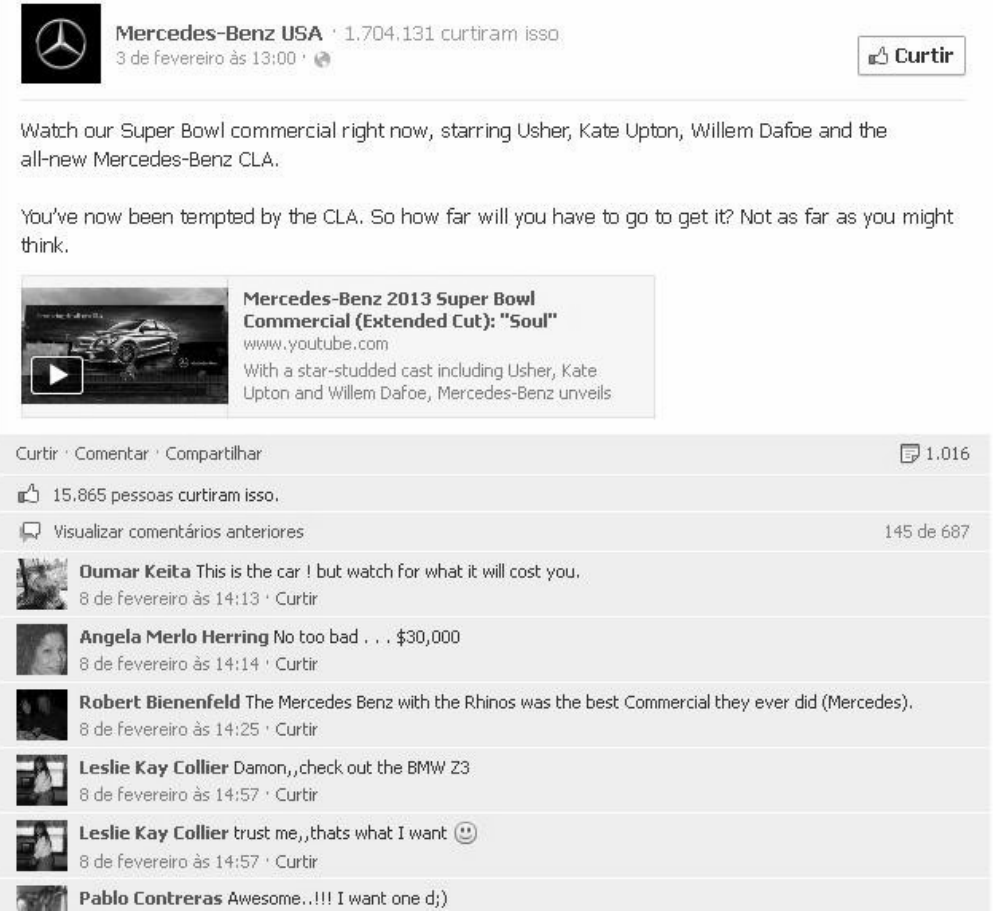

Imagem 7: Fanpage da Mercedes-Benz USA

\subsection{Novo Classe A "AAA Lek Lek Lek"}

Lançado em abril de 2013, o vídeo foi produzido pela agência de publicidade Tesla (http://www.youtube.com/watch?v=wk3tf5SLmPs) e veiculado no Youtube e na Fanpage da Mercedes-Benz. Logo no início, chama a atenção, não tanto pelas imagens, mas pela trilha, o funk "passinho do volante". Em relação à estética da imagem, o vídeo é semelhante ao primeiro, pois um tom azul marinho metálico também predomina na tela, as luzes dos faróis dianteiros do carro e do chão, realizam um efeito similar aos dos flashes. Pelo tom azul e lu- 
zes dos faróis, percebe-se que o carro se movimenta em um ambiente à noite, ressaltando as linhas do projeto aerodinâmico do carro, refletindo em um jogo de sombra e luz. Além disso, o carro faz curvas sobre o chão molhado, que no escuro, brilha sob o efeito de luzes intensas, conforme se observa no vídeo, corroborando com o slogan apresentado no site da Mercedes-Benz sobre o modelo Novo Classe A: “Faz tempo que seus olhos não brilham assim”. Já as luzes vermelhas dos faróis traseiros do carro, produzem o efeito idêntico a o da boate do vídeo anterior, assim como o cenário que também é iluminado no tom azul, assemelhando-se a uma passarela, sobre a qual o carro desfila.

Segundo o site de comunicação Meio\&Mensagem, trechos da música como "Girando, girando, girando para o lado. Girando, girando, girando pro outro" combinariam com os movimento do carro que gira com naturalidade. Além disso, o carro, assim como passistas na dança, possui estabilidade e não sai do chão nas manobras. (Imagem 8).

Neste vídeo, a câmera foca nos detalhes exteriores do carro, e apenas uma vez, na parte interna, mostrando a facilidade do motorista ao manobrar nas curvas com apenas uma mão ao volante.

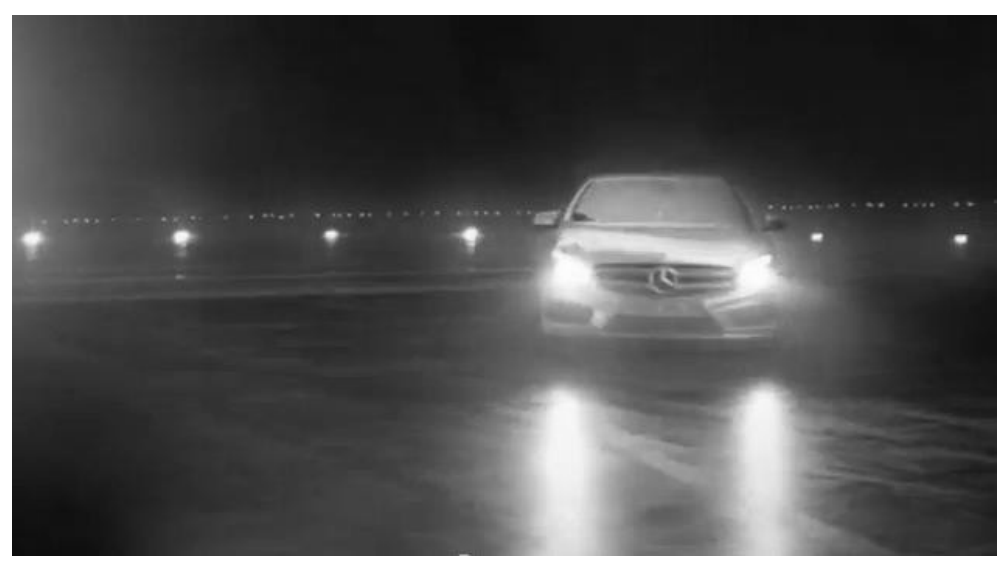

Imagem 8: O carro girando para um lado

Se observa que o carro segue a letra da música, quando se escuta que "é possível girar, até no passinho do volante” (Imagem 9). O vídeo se apropria da música para demonstrar as características que o carro possui, como por exemplo, a facilidade de realizar manobras ou a eficiência do freio. 


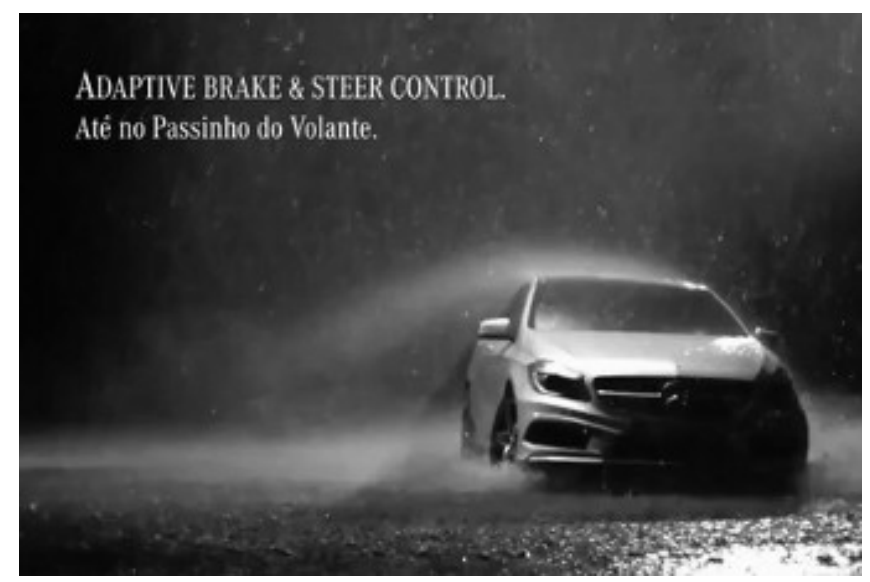

Imagem 9: O carro girando para outro lado e a frase "Até no passinho do Volante"

Quando a música atinge a estrofe, surge na tela a letra A maiúscula e no fundo musical, ouve-se “Aaah lelek lek lek lek lek lek lek lek lek lek” (Imagem 10), anunciando o carro Novo Classe A.

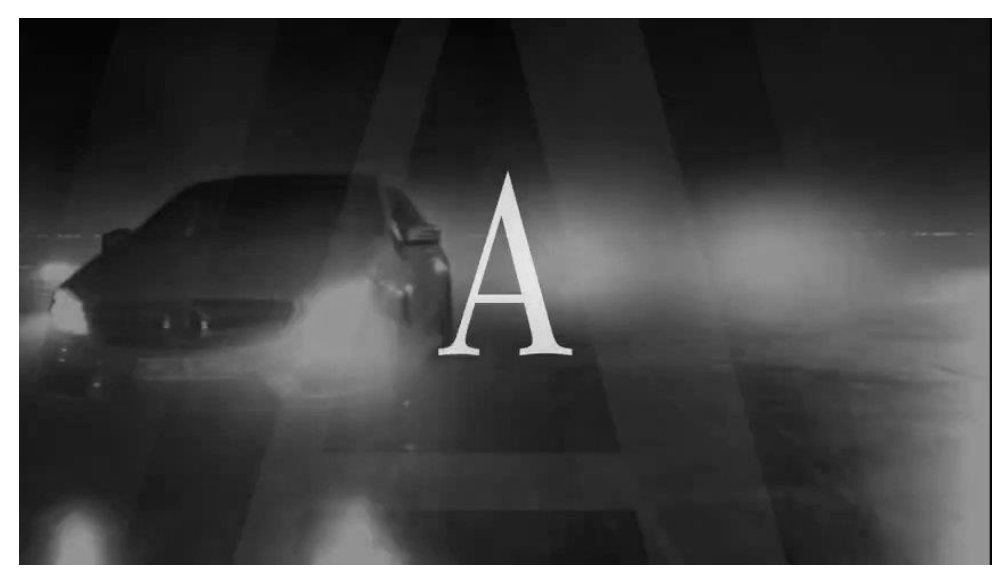

Imagem 10: A letra "A" no vídeo

Ao final, o vídeo mostra o carro com a frase "Novo Classe $A$, a letra que veio da vontade de inovar" (Imagem 11). Os modelos de automóveis da Mercedes-Benz são classificados como classes seguidas de letras. No caso do vídeo, A letra " $A$ " reforça o modelo do automóvel, cuja letra qualifica o carro como "Kompaktklasse" - classe compacta, combinado com a trilha, cujo refrão também é marcado peça sonoridade da letra "AAAAAA lek lek...". A conjugação destes elementos, com o acréscimo da frase "A letra que veio da vontade de inovar" assinala também, a escolha de um funk para compor a trilha deste vídeo, que resultou em enorme repercussão nas redes sociais digitais. Neste texto, podemos perceber que estão inovando não apenas no modelo do carro, 
mas também na maneira de realizar os vídeos publicitários da marca, sendo mais ousados ao colocar o Funk como trilha sonora e não mostrando explicitamente as representações de sucesso e fama, mas implicitamente, através do cenário e do jogo de luzes utilizado.

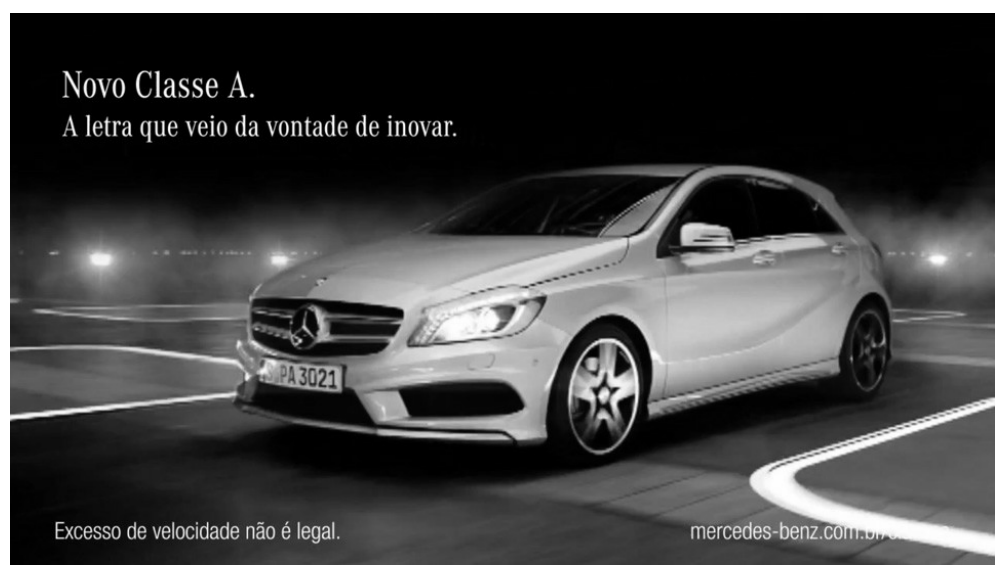

Imagem 11: A última imagem do vídeo.

Na postagem do vídeo na Fanpage da Mercedes-Benz, que possui 39.801 fãs, houve 182 comentários, a maioria com conteúdo negativo (normalmente, a média é de 10 comentários por postagem), 321 curtidas e 378 compartilhamentos. Esta polêmica criada nas redes sociais a partir da veiculação deste vídeo (Imagem 12) deve-se ao fato deste não ser identificado às características identitárias da Mercedes-Benz, no que se refere ao seu imaginário. Ele parece ser uma ação isolada e não uma tendência da Mercedes. Esta ideia é reforçada na entrevista de Jaime Troiano, CEO do Grupo Troiano, para o portal Mundo do Marketing (http://www.mundodomarketing.com.br/): “Estamos falando de uma marca que se chama Mercedes-Benz, com longa tradição de estilo, exclusivo, que vale o que vale justamente por não ser um carro acessível a todos. Isso é justamente o contrário da aura da marca, que é bacana justamente por não ser acessível”. 


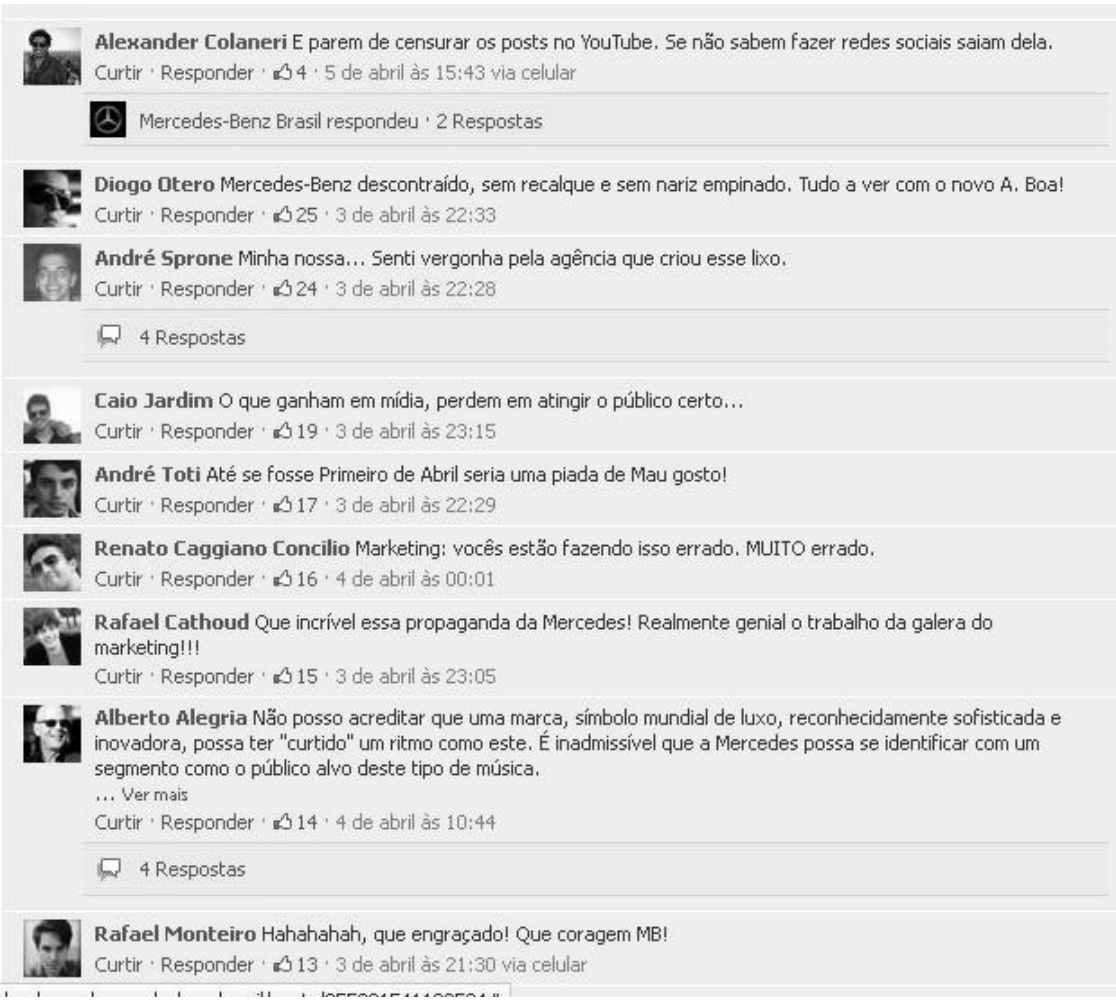

Imagem 12: Polêmica nas redes sociais da Fanpage da Mercedes-Benz Brasil

Em entrevista concedida ao site Mundo do Marketing, o gerente de comunicação da Mercedes-Benz ressalta: "O objetivo não é vender o carro, mas chamar a atenção para o lançamento, mostrando que a marca está com um posicionamento mais agressivo, jovem, audacioso e ousado, além de criar o burburinho nas redes sociais e fazer as pessoas terem interesse em entrar no hotsite".

A declaração acima sugere que a inovação não diz respeito apenas ao modelo do carro, mas se refere também à produção do vídeo analisado, com ambos tentando atingir um público mais jovem. Por outro lado, como afirma o profissional especializado em marcas, Jaime Troiano, a estratégia seria errônea ao introduzir no vídeo, uma trilha sonora popular, difundindo a ideia de que o carro seria uma possibilidade para a maioria.

\section{CONSIDERAÇÕES FINAIS}

Com base nesta análise, percebemos alguns pontos em que os vídeos se relacionam. Primeiramente, o jogo de luzes utilizado nos dois vídeos, representando a fama, remete ao luxo da marca. O cenário em tom azul e a ideia de 
passarela do segundo vídeo, é semelhante ao da boate do primeiro vídeo, no qual o jovem dança com o músico Usher.

Enquanto o primeiro vídeo apresenta um enredo com início, meio e fim, utilizando uma música em estilo rock, cujo título "Sympathy for the Devil" faz alusão à história contada, o segundo mostra apenas o carro, sem a utilização de uma narrativa, além de promover a relação dos movimentos do carro com a música em estilo Funk.

Percebe-se que a estratégia utilizada pela Mercedes-Benz no Brasil, para o modelo Novo Classe A, promove, concomitantemente, as características identitárias da empresa ligadas ao luxo e ao status, graças a sua estética, e as características relacionadas ao imaginário do funk carioca, através da veiculação da música "Passinho no Volante". Neste ponto, compreende-se o estabelecimento de uma relação dialógica entre os elementos do vídeo, que se referem ao carro, ao cenário futurístico e ao funk. Conexões observadas no vídeo publicitário que causaram polêmica e dividiram opiniões em sites especializados, fóruns de discussão e redes sociais na internet. Na Fanpage oficial da Mercedes-Benz Brasil, observam-se reclamações dos fãs a respeito do vídeo (Imagem 12).

Mesmo que a coreografia da música "Passinho no volante" seja vista nas comemorações de alguns atletas consagrados nos seus respectivos esportes e o estilo Funk seja consumido por todo tipo de público, pode se observar que o vídeo da música "Passinho no volante", foi realizado em uma favela. Este ambiente é frequentemente relacionado a um imaginário de pobreza e exclusão.

Neste sentido, pode ocorrer um choque de imaginários, gerador de uma crise de imagem, resultado da estética do vídeo, congruente com o que se espera da marca e a trilha, que independentemente dos resultados futuros para a marca, inovou, ao afastar-se do estilo de música instrumental, normalmente utilizado nos vídeos da Mercedes. A identidade da empresa não foi desconstruída ou alterada, pois seria preciso mais do que uma ação isolada para que isto acontecesse.

Mesmo que o objetivo, nos dois vídeos, seja o mesmo, o de apresentar o carro "popular" da Mercedes para um novo público (mais jovem), observamos que o primeiro vídeo não causou polêmica entre os fãs no Facebook (Imagem 7), enquanto o segundo causou uma diversidade de opiniões dividindo até mesmo profissionais da área do marketing. Após a polêmica gerada pelo vídeo publicitário da Mercedes-Benz, o vídeo alcançou milhares de visualizações, 
mas este fato não dá indícios de que estes números se converterão em vendas do carro Novo Classe A.

\section{REFERÊNCIAS}

BITTAR, Danielle Tristão. A imagem da Mercedes-Benz em juiz de fora. Universidade Federal de Juiz de Fora. 2012

COELHO, Anna Elisa Nunes N. B. A música como diferencial competitivo na publicidade: As trilhas sonoras dos comerciais em função da segmentação de mercado. UNICEUB, 2008, 32 p. Monografia apresentada ao Centro Universitário de Brasília - UniCEUB, como requisito parcial para a obtenção de grau de bacharel em Comunicação Social, habilitação em Publicidade e Propaganda. Brasília, 2008.

COSTA, Joan. Imagen corporativa en el siglo XXI. Buenos Aires: La Crujía Ediciones, 2001. KUNSCH, Margarida Maria K. Planejamento de Relações Públicas na Comunicação Integrada - nova edição revisada, atualizada e ampliada. São Paulo: Summus, 2003

DE DEUS, Andreia Morais; DE ASSIS, Érika Correia Frutuoso. O Som da Propaganda: Possíveis Relações Imagético-Sonoras Com a Estética de Videoclipe. Universidade Federal FREIRE, Libny Silva. Nem luxo, nem lixo: Um olhar sobre o funk da ostentação. IX POSCOM, Rio de Janeiro, 2012.

GRIMSON, A., "Culture and Identity: two different notions", in: Social Identities, vol. 16, $n^{\circ} 1$, January 2010, pp. 63-79.

LOURO, Maria João Soares. Modelos de avaliação de marca. Rev. adm. empres. [online]. 2000, vol.40, n.2, pp. 26-37.

MAFFESOLI, Michel. O mistério da conjunção: ensaios sobre comunicação, corpo e sociabilidade. Tradução de Juremir Machado da Silva. Porto Alegre: Sulina, 2005.

to, 2001 .O imaginário é uma realidade. In: Revista Famecos. Porto Alegre, $n^{\circ}{ }^{15}$, agos-

MENDONÇA, Vanderlei Cristo. A identidade funkeira e a luta contra a incriminação e discriminação da juventude pobre a partir do funk. Anais do Seminário Nacional da Pós-Graduação em Ciências Sociais UFES. v. 1, n. 1, 2011.

VASQUEZ, Ruth Peralta. Identidade de marca, gestão e comunicação. Revista Organicom. São Paulo, ano 4, n. 7, jun/dez 2007, p. 198-211

VIANNA, Hermano. Funk e cultura popular carioca. Estudos Históricos, Rio de Janeiro, vol. 3, n. 6, 1990, p. 244-253

Links:

Site da Mercedes-Benz. Disponível em: <http://www.mercedes-benz.pt/content/portugal/ $\mathrm{mpc} / \mathrm{mpc}$ _portugal_website/ptng/home_mpc/passengercars.html> Acesso em: 08/04/2013 
O Funk. Disponível em: <https://pt.wikipedia.org/wiki/Funk> Acesso em: 08/04/2013

REPORTER TERRA. A história do Funk. Disponível em: <http://www.terra.com.br/reporterterra/funk/historia_do_funk.htm> Acesso em: 14/04/2013

GAZETA ONLINE. MC Federado e os Lelekes comemoram música em propaganda da Mercedes. Disponível em: <http://gazetaonline.globo.com/_conteudo/2013/04/voce_ag/tv_e_famosos/noticias/1427420-mc-federado-e-os-lelekes-comemoram-musica-em-propaganda-damercedes.html> Acesso em: 14/04/2013

DE PINO, RAFAEL. O Funk da ostentação em São Paulo. Disponível em: <http://revistaepoca. globo.com/cultura/noticia/2012/og/o-funk-da-ostentacao-em-sao-paulo.html> Acesso em: 14/04/2013

TURLÃO FELIPE. Lelek Lek e Mercedes-Benz Combinam? Disponível em: <http://www.meioemensagem.com.br/home/comunicacao/noticias/2013/04/04/Lelek-Lek-e-Mercedes-Benzcombinam.html> Acesso em: 17/04/2013

O CIDADÃO. Mercedes lança comercial do novo classe A com música ah lelek. Disponível em: <http://ocidadaorj.com.br/site/2013/04/o7/mercedes-lanca-comercial-do-novo-classe-acom-musica-ah-lelek/> Acesso em: 17/04/2013

REDAÇÃO INFO. A polêmica do Classe A e o funk "Lek Lek" <http://quatrorodas.abril.com. br/noticias/fabricantes/polemica-classe-funk-lek-lek-737776.shtml> Acesso em: 04/06/2013

RECEBIDO EM: 24/05/2013

ACEITO PARA PUBLICAÇÃO: 28/06/2013 


\section{Jorge Francisco Puente Arnao Galarreta}

Autor do trabalho, Bacharel do Curso de Comunicação Social - Hab. Relações Públicas, da UFSM, Mestrando em Comunicação Midiática, Linha Mídias e Identidades Contemporâneas. Bolsista CAPES.

\section{Ada Cristina Machado Silveira}

Orientadora do trabalho, Dra. em Jornalismo pela Universidade Autônoma de Barcelona, professora associada III do Departamento de Ciências da Comunicação e nos Programas de Pósgraduação em Comunicação e Extensão rural da UFSM.

\section{Isabel Padilha Guimarães}

Co-autora, Dra. em Comunicação Social, bolsista de Estágio pós doutoral DOCFIX - Capes - Fapergs, no Programa de Pós-graduação em Comunicação da UFSM. 